\section{Implantation of a customized toric intraocular lens for correction of post- keratoplasty astigmatism}

\begin{abstract}
Purpose To report visual and refractive outcomes, and endothelial cell loss following primary and secondary 'piggyback' toric intraocular lens (IOL) implantation in patients with high post-penetrating keratoplasty (PK) astigmatism.

Methods Prospective case series. Nine eyes of nine patients with post-PK astigmatism were consecutively recruited for implantation of a customized toric IOL. Six underwent simultaneous phacoemulsification (PE) and three pseudophakic eyes had a secondary 'piggyback' toric IOL implanted in the ciliary sulcus. Mean follow-up time was $17.2 \pm 7.7$ months. Pre- and post-operative uncorrected (UDVA) and best-corrected (BDVA) distance visual acuities and refractive errors were collected for comparison. Cartesian astigmatic vectors were calculated to identify a change in the magnitude of astigmatism precompared to postoperatively. Pre- and postoperative endothelial cell counts were also collected for analysis.

Results UDVA (logMAR) improved from $1.13 \pm 0.51$ preoperatively to $0.48 \pm 0.24$ postoperatively $(P$-value $=0.003)$. There was no significant change in BDVA

$(P$-value $=0.905)$ from $0.31 \pm 0.27$ to $0.26 \pm 0.19$. Corneal astigmatism preoperatively was $6.57 \pm 4.40$ diopters (D). Post-operative refractive cylinder was $0.83 \pm 1.09 \mathrm{D}$ compared to $3.89 \pm 4.01 \mathrm{D}$ preoperatively $(P=0.039)$. Analysis of astigmatic Cartesian $x$ and $y$ coordinates found a significant reduction postoperatively compared to preoperatively $(P=0.005$ and $P=0.002)$, respectively. Mean endothelial cell loss was $9.9 \%$. Conclusion: Implantation of a customized primary or secondary 'piggyback' toric IOL
\end{abstract}

S Srinivasan ${ }^{1,2}$, DSJ Ting ${ }^{1}$ and DAM Lyall ${ }^{1}$



serves as an effective modality in treating patients with high post-PK astigmatism. Eye (2013) 27, 531-537; doi:10.1038/eye.2012.300; published online 25 January 2013

Keywords: penetrating keratoplasty; astigmatism; toric intraocular lens

\section{Introduction}

Despite the advancement in instrumentations and microsurgical skills, astigmatism remains a major issue following penetrating keratoplasty (PK). It has been reported that astigmatism induced by PK can be as high as 4-6 diopters (D) $, 1,2,3$ thus severely undermining the visual outcome following transplantation. A broad spectrum of therapeutic modalities has been proposed and employed to correct post-PK astigmatism. Choices of treatment are largely dependent on the severity of astigmatism. Conservative measures like spectacles or contact lens wear can be used to correct mildmoderate astigmatism. However, this might not be suitable in patients with anisometropia or those intolerant to contact lens wear.

Alternatively, treatments like selective suture removal, relaxing incisions, wedge resections, compression sutures, photorefractive keratectomy (PRK), and laser-assisted in situ keratomileusis (LASIK) all serve as feasible options in correcting astigmatism. ${ }^{2-5}$ There is emerging evidence advocating the use of customized toric intraocular lens (IOL) as a novel approach to correct high post-PK astigmatism. ${ }^{6,7}$

Not uncommonly, patients with post-PK astigmatism can also develop cataract in the previously operated eye at the later stage of
'Department of Ophthalmology, University Hospital Ayr, Ayr, Scotland, UK

${ }^{2}$ Faculty of Medicine, University of Glasgow, Glasgow, Scotland, UK

Correspondence: S Srinivasan, Department of Ophthalmology, University Hospital Ayr, 3rd Floor, Dalmellington Road, Ayr, Scotland KA6 6DX, UK. Tel: + 441292 614843, Fax: + 441292614646 E-mail: sathish. srinivasan@gmail.com

Received: 28 June 2012 Accepted in revised form: 13 December 2012 Published online: 25 January 2013

Previous Presentation: American Academy of Ophthalmology Annual Meeting, October 2010, Chicago, USA 
their lives. This has prompted the idea of performing phacoemulsification (PE) with toric IOL implantation to correct both post-PK astigmatism and cataract simultaneously. Nonetheless, there are very limited data available in the literature reporting the outcome of this approach, and most of them are of case reports or small case series. ${ }^{8-11}$ Stewart and McAlister ${ }^{12}$ had recently reported good visual outcome following toric IOL implantation with simultaneous cataract surgery in eight patients with post-PK astigmatism and cataract. However, this was conducted as a retrospective study and endothelial cell loss, which represents a major concern in post-PK patient undergoing cataract surgery, was not analyzed. In this prospective study, we aim to examine and analyze the visual and refractive outcomes, and endothelial cell loss following implantation of toric IOL with or without simultaneous PE in nine patients with post-PK astigmatism.

\section{Patients and methods}

This study was designed as a prospective, noncomparative, interventional case series. Nine patients who presented to the corneal service at University Hospital Ayr (Ayr, Scotland, UK) with post-PK astigmatism with or without co-existing cataract between March 2009 and May 2011 were consecutively enrolled into this study. Six of these nine patients (66.6\%) attempted but subsequently became intolerant to contact lens wear. Subjects underwent primary toric IOL implantation during cataract surgery, and in previously pseudophakic eyes a customized secondary 'piggyback' toric IOL implant was placed in the ciliary sulcus. All patients undergoing primary toric IOL implantation had visually significant cataract and none had clear lens extraction.

\section{Pre-operative assessment}

All patients underwent a comprehensive pre-operative assessment that included uncorrected distance visual acuity (UDVA), best-corrected distance visual acuity (BDVA), slit-lamp examination, optical biometry (Carl Zeiss IOL Master V.5.4.1, Carl Zeiss Meditec, Jena, Germany) ultrasound pachymetry, corneal topography, and specular microscopy (EM-3000; Tomey, Phoenix, AZ, USA). The toric IOL was customized and ordered from specific manufacturers. The power of the IOL, including the cylindrical value and meridian of the IOL, was calculated using proprietary software licensed to the company providing the lens. So as to eliminate any contribution of astigmatism induced by the crystalline lens, keratometric values measured using the IOL Master were used when calculating the IOL power, rather than the refractive cylindrical error. The IOL design chosen in each case was dependant on the range of toricity available with each IOL design. Emmetropia was the desired refractive outcome following toric IOL implantation. The preoperative characteristics of the cohort are summarized in Table 1.

\section{Inclusion/exclusion criteria}

Both phakic patients with cataract and pseudophakic patients were excluded if they had any visually significant ocular pathology or history of previous ocular surgery other than that relating to corneal transplantation and correction of astigmatism, such as wedge excision. Previous refractive laser surgery was an exclusion criteria as it was considered that this may affect the predictability of IOL power calculation. Patients were excluded if signs of endothelial failure were present. Patients were considered for a toric IOL if symptoms relating to their corneal astigmatism could not be adequately corrected with spectacles, or if they were intolerant, or did not wish to consider contact lenses.

\section{Intraocular lenses}

One of three IOLs were used in this study. In patients undergoing primary IOL implantation, the T-flex (Rayner, Hove, UK) was preferentially used. In patients undergoing secondary 'piggyback' toric IOL implantation, the Sulcoflex (Rayner, Hove, UK) was preferentially used. If the required IOL cylindrical power was greater than that available in either the T-flex or Sulcoflex range, the Torica-s IOL (Humanoptics, Erlangen, Germany) was used instead. The T-flex is an injectable, single piece, hydrophilic acrylic IOL with square edge, optic diameter of either 5.75 or $6.25 \mathrm{~mm}$ and overall length of 12.0 or $12.5 \mathrm{~mm}$. IOL toricity is available up to $+11 \mathrm{D}$. The Torica-s is a foldable, three-piece silicone IOL with Z-shaped haptics and a sharp-edged optic. Optic diameter is $6.0 \mathrm{~mm}$ and overall length is $11.6 \mathrm{~mm}$. IOL toricity is available up to $+30.0 \mathrm{D}$. The Sulcoflex is an injectable, single piece, hydrophilic acrylic IOL with a rounded edge. Optic diameter is $6.5 \mathrm{~mm}$, overall length is $14.0 \mathrm{~mm}$, and toricity is available up to $+6.0 \mathrm{D}$. Haptics are posteriorly angulated at $10^{\circ}$ to the optic so as to avoid pigment dispersion and iris capture of a sulcus-fixated IOL. The power of each IOL, including the spherical and cylindrical values and recommended axis, was calculated using proprietary software licensed to the company providing the lens. 
Table 1 Pre-operative, intraoperative, and post-operative characteristics of the cohort

\begin{tabular}{|c|c|c|c|c|c|c|c|c|c|c|c|c|c|c|}
\hline \multirow[t]{2}{*}{ Patient } & \multirow{2}{*}{$\begin{array}{c}\text { Age } \\
\text { (years) }\end{array}$} & \multirow[t]{2}{*}{ Gender } & \multirow{2}{*}{$\begin{array}{l}\text { Initial } \\
\text { diagnosis }\end{array}$} & \multirow{2}{*}{$\begin{array}{l}P K \rightarrow \text { toric } \\
\text { IOL }(\text { years })^{*}\end{array}$} & \multicolumn{4}{|c|}{ Pre-operative } & \multirow[t]{2}{*}{ Procedure } & \multirow{2}{*}{$\begin{array}{l}\text { Types of } \\
\text { toric IOL }\end{array}$} & \multicolumn{4}{|c|}{ Post-operative } \\
\hline & & & & & $U D V A$ & $B D V A$ & $\begin{array}{c}C C y l \\
(D)\end{array}$ & $E C D$ & & & $U D V A$ & $B D V A$ & $\begin{array}{c}R C y l \\
\text { (D) }\end{array}$ & $E C D$ \\
\hline 1 & 50 & Male & Keratoconus & 17 & 2 & 0 & 4.49 & 1037 & $\begin{array}{l}\text { Phaco }+ \\
\text { toric IOL }\end{array}$ & $\begin{array}{l}\text { Rayner } \\
\text { T-flex }\end{array}$ & 0.3 & 0.2 & 0 & 927 \\
\hline 2 & 56 & Male & FED & 27 & 0.8 & 0.2 & 9.02 & 1196 & $\begin{array}{l}\text { Piggyback } \\
\text { toric IOL }\end{array}$ & $\begin{array}{l}\text { Rayner } \\
\text { sulcoflex }\end{array}$ & 0.6 & 0.2 & 3.5 & 1049 \\
\hline 3 & 75 & Male & FED & 4 & 2 & 0.3 & 9.58 & 1381 & $\begin{array}{l}\text { Piggyback } \\
\text { toric IOL }\end{array}$ & $\begin{array}{l}\mathrm{HO} \\
\text { PCIOL }\end{array}$ & 1 & 0.5 & 1 & 1174 \\
\hline 4 & 80 & Male & Stromal scar & 14 & 1 & 0.2 & 12.63 & 1232 & $\begin{array}{l}\text { Phaco }+ \\
\text { toric IOL }\end{array}$ & $\begin{array}{l}\mathrm{HO} \\
\text { PCIOL }\end{array}$ & 0.3 & 0.3 & 0.5 & 1071 \\
\hline 5 & 76 & Female & $\begin{array}{l}\text { Herpetic } \\
\text { keratitis }\end{array}$ & 18 & 0.8 & 0.5 & 12.67 & 1028 & $\begin{array}{l}\text { Phaco + } \\
\text { toric IOL }\end{array}$ & $\begin{array}{l}\mathrm{HO} \\
\text { PCIOL }\end{array}$ & 0.6 & 0.6 & 1 & 981 \\
\hline 6 & 58 & Male & $\begin{array}{l}\text { Herpetic } \\
\text { keratitis }\end{array}$ & 7 & 1 & 0 & 1.81 & 1484 & $\begin{array}{l}\text { Phaco }+ \\
\text { toric IOL }\end{array}$ & $\begin{array}{l}\text { Rayner } \\
\text { PCIOL }\end{array}$ & 0.5 & 0 & 0.5 & 1022 \\
\hline 7 & 64 & Male & $\begin{array}{l}\text { Herpetic } \\
\text { keratitis }\end{array}$ & 32 & 1 & 0.8 & 1.62 & 1915 & $\begin{array}{l}\text { Phaco }+ \\
\text { toric IOL }\end{array}$ & $\begin{array}{l}\text { Rayner } \\
\text { T-flex }\end{array}$ & 0.5 & 0.2 & 0 & 1795 \\
\hline 8 & 67 & Female & FED & 3 & 1 & 0.2 & 1.74 & 1017 & $\begin{array}{l}\text { Piggyback } \\
\text { toric IOL }\end{array}$ & $\begin{array}{l}\text { Rayner } \\
\text { sulcoflex }\end{array}$ & 0.2 & 0.2 & 1 & 865 \\
\hline 9 & 73 & Male & Keratoconus & 40 & 0.6 & 0.6 & 7.09 & 1155 & $\begin{array}{l}\text { Phaco }+ \\
\text { toric IOL }\end{array}$ & $\begin{array}{l}\text { Rayner } \\
\text { T-flex }\end{array}$ & 0.3 & 0.1 & 0 & 1120 \\
\hline
\end{tabular}

Abbreviations: C Cyl (D), corneal cylinder (diopter); CDVA, corrected distance visual acuity; ECD, endothelial cell density (cells/mm²); FED, Fuchs' endothelial dystrophy; HO,Human Optics; PK, penetrating keratoplasty; R Cyl (D), Refractive cylindrical error (diopters); UDVA, uncorrected visual acuity.

*Time interval between PK to toric IOL implantation (years)

\section{Surgical procedure}

All the procedures were performed under combined topical (proxymethocaine, Chauvin Pharmaceuticals, Romford, England) and intracameral anesthesia (preservative free 1\% lidocaine, Baxter, Theford, UK) by a corneal surgeon (SS). Prior to the surgery, using a slit lamp the horizontal and the vertical corneal meridian were marked in all subjects so as to avoid the effects of cyclotorsion in the supine position. Preoperatively the pupils were dilated with $10 \%$ phenylepherine and $1 \%$ cyclopentolate eye drops. A Mendez gauge was used to mark to steep corneal meridian at the beginning of the operation. The surgeon's preference was to operate superiorly through a posterior limbal incision. As he was right handed, the main incision was made at $100^{\circ}$ on right eyes, and at $90^{\circ}$ on left eyes. The T-flex and Sulcoflex are injectable through a $2.75 \mathrm{~mm}$ incision, whereas a larger $3.5 \mathrm{~mm}$ incision was required to accommodate the foldable Torica-s with larger Z-haptic design. The surgeon's pre-calculated surgically induced astigmatism of $0.50 \mathrm{D}$ through a $2.75 \mathrm{~mm}$ wound was accounted for when calculating IOL spherical and cylindrical power for both Rayner and HumanOptics IOLs. A 'soft shell' technique was used to protect the corneal endothelium. Six of the nine eyes underwent PE combined with implantation of a toric IOL within the capsular bag, whereas three pseudophakic eyes had a secondary 'piggyback' toric IOL placed in the ciliary sulcus. A pupil-expanding device (6.25 mm Malyugin Ring) was used in all the cases that underwent PE due to poor pharmacological dilatation. At the end of the procedure, intracameral cefuromixe $(1.0 \mathrm{mg}$ in $0.1 \mathrm{ml})$ and subconjunctival injection of betamethasone was administered. The posterior limbal wound in all cases was secured with a single 10-0 nylon suture. Postoperatively, all were treated with topical $1 \%$ prednisolone acetate (Pred Forte, Allergan, Irvine, CA, USA) six times a day and topical $0.3 \%$ ofloxacin (Exocin, Allergan) four times a day. The topical antibiotic and steroid was continued for 4 weeks, following which the topical antibiotic was discontinued, whereas the dose of topical steroids was titrated based on the clinical response. Post-operative follow-up examinations were scheduled at the following time gate: 1 day, 1 week, 1 month, 3 months, 6 months, and 6 monthly thereafter. The corneal suture was removed during the 1-month post-operative visit in all cases.

\section{Outcome measures}

This included visual (UDVA and BDVA) and refractive outcome including mean spherical equivalent (MSE), specular microscopy, and assessment of surgically induced astigmatism by vector analysis. Snellen acuities were converted to $\log$ MAR for statistical analysis. Visual 
outcome was determined by the post-operative UDVA and BDVA at last follow-up.

The equivalent magnitude of pre- and post-operative refractive errors were calculated in the corneal plane using commercially available software (EyePro 2011 EB EYE Limited 2009-2011). This allowed direct comparison of refractive cylindrical error with keratometric astigmatic values. These were then expressed in Cartesian form: $x$ (Jackson cross cylinder (JCC) at axis $0^{\circ}$ ) and y (JCC at axis $45^{\circ}$ ) using the same software. Conversion to Cartesian notation allowed direct comparison between astigmatic errors regardless of the meridian of astigmatism. The corneal plane value of the post-operative refractive cylindrical error was calculated using the formula $\operatorname{Ref}_{C}=\operatorname{Ref}_{S} /\left(1-\left(\right.\right.$ vertex $\left.\left.\times \operatorname{Ref}_{S}\right)\right)$, where $\operatorname{Ref}_{C}$ is the refractive power in the corneal plane and $\operatorname{Ref}_{S}$ is the refractive power in the spectacle plane. ${ }^{13}$ All refractions had been performed with a back vertex distance of $12 \mathrm{~mm}$. The $x$ Cartesian coordinate of each astigmatic vector was calculated using the formula (cylindrical error $\times \cos 2$ (axis)) and the y coordinate was calculated by (cylindrical error $\times \sin 2$ (axis)). This method has previously been described by Holladay et al. ${ }^{13}$

\section{Statistical analysis}

A proprietary software package SPSS v14.0 (IBM, Armonk, NY, USA) was used for statistical analysis. Twotailed paired $t$-test was used to examine the significant differences between pre-operative and post-operative UDVA, BDVA, cylindrical error, and endothelial cell density (ECD). Levene test was used to assess the equality of variance between pre- and post-operative Cartesian values. An improvement in astigmatism can be regarded as a reduction in variance around the value 0 (ie, astigmatically neutral). $P$-value $<0.05$ was considered statistically significant. All data were presented as mean \pm SD.

\section{Results}

A total of nine eyes of nine patients were recruited and operated. One patient experienced subincisional iridodialysis intraoperatively with a resultant enlarged post-operative pupil aperture. There were no other intraoperative complications. The mean age of the cohort was $66.6 \pm 10.3$ (SD) years and six $(66 \%)$ were male patients. Mean follow-up period was 17.2 \pm 7.7 months (range 7-31). Six (66\%) patients underwent simultaneous toric IOL implantation and PE, whereas the other three (33\%) underwent secondary piggyback toric IOL implantation. The mean interval from PK to toric IOL implantation was $17.1 \pm 12.8$ years.

\section{Visual outcome}

The mean UDVA (log MAR) improved from $1.13 \pm 0.51$ preoperatively to $0.48 \pm 0.24$ postoperatively at the last follow-up. $(P$-value $=0.003)$ (Figure 1, Tables 1 and 2). Postoperatively, eight $(88.9 \%)$ patients attained an UDVA of $\geq 6 / 24$ and four (44.4\%) had an UDVA $\geq 6 / 12$ (Table 1). Mean pre-operative BDVA was $0.31 \pm 0.27$ compared to $0.26 \pm 0.19$. postoperatively $(P$-value $=0.905)$.

Rigid-gas permeable contact lenses were not considered postoperatively to further improve BDVA, as patients were either previously intolerant to their use preoperatively or did not wish to try them.

\section{Refractive outcome}

Preoperatively, the mean MSE and cylindrical errors were $-4.58 \pm 4.03 \mathrm{D}$ and $3.89 \pm 4.01 \mathrm{D}$, respectively. Mean pre-operative corneal cylindrical error was $6.57 \pm 4.40 \mathrm{D}$. Postoperatively, the mean MSE improved to $0.00 \pm 1.21 \mathrm{D}(P=0.01)$. The cylindrical error improved to $0.83 \pm 1.09 \mathrm{D}$ postoperatively $(P=0.039)$.

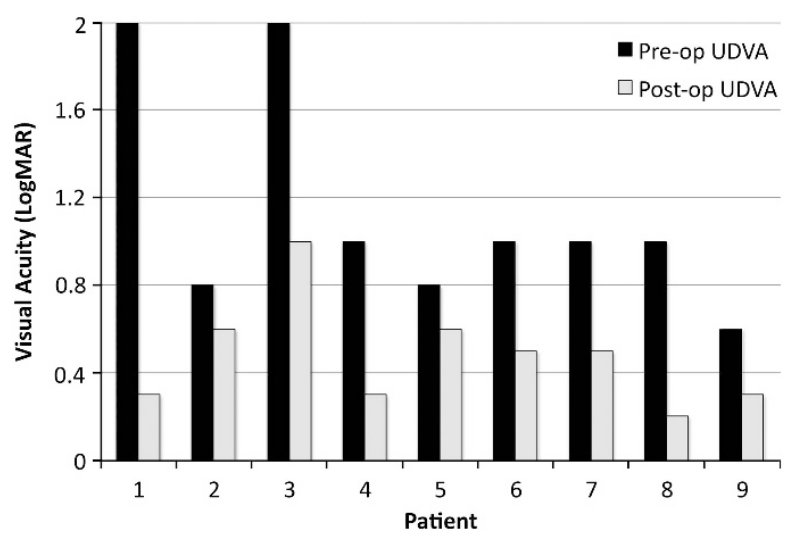

Figure 1 Post-operative compared to pre-operative UDVA of individual patients.

Table 2 Visual and refractive outcomes

\begin{tabular}{lrrl}
\hline & \multicolumn{2}{c}{ Toric IOL implantation } & P-value* \\
\cline { 2 - 3 } & Pre-operative & $\begin{array}{c}\text { Post- } \\
\text { operative }\end{array}$ & \\
\hline UDVA & $1.13 \pm 0.51$ & $0.48 \pm 0.24$ & 0.003 \\
CDVA & $0.31 \pm 0.27$ & $0.30 \pm 0.25$ & 0.905 \\
$\begin{array}{l}\text { Mean spherical equivalent } \\
\text { (D) }\end{array}$ & $-4.58 \pm 4.03$ & $0.00 \pm 1.21$ & 0.01 \\
$\begin{array}{l}\text { Refractive cylindrical error } \\
\text { (D) }\end{array}$ & $3.89 \pm 4.01$ & $0.83 \pm 1.09$ & 0.039 \\
ECD (cells $/ \mathrm{mm}^{2}$ ) & $1271 \pm 290$ & $1124 \pm 273$ & 0.009 \\
\hline
\end{tabular}

CDVA, corrected distance visual acuity; ECD, endothelial cell density (cells $/ \mathrm{mm}^{2}$ ); UDVA, uncorrected distance visual acuity.

Data presented are means $\pm \mathrm{SD}$. ${ }^{*}$ Two-tailed paired $t$-test was used. $P$-value $<0.05$ was considered statistical significant. 
Figure 2 compares the pre-operative corneal astigmatic vectors with the post-operative refractive cylindrical vectors when the values have been re-adjusted for the corneal plane so as to allow direct comparison. The mean Cartesian coordinates of the post-operative refractive cylindrical error in the corneal plane were $(-0.61$ and $-0.45)$ with a SD of \pm 0.92 and \pm 0.78 , respectively. This is in comparison to a mean pre-operative corneal astigmatic error of $(+1.92$ and +2.63$)$ with a SD of \pm 6.69 and \pm 3.36 , respectively (Figure 3 ). Such values were calculated using astigmatic values measured by the IOL Master. Levene test for homogeneity of variances found that there was a significant reduction in variance for both the $\mathrm{x}(P=0.005)$ and $\mathrm{y}(P=0.002)$ coordinates postoperatively compared to preoperatively.

As a coordinate of $(0,0)$ represents an eye that is free of astigmatic error, one can conclude that there is a significant reduction in astigmatism postoperatively in our cohort, as the post-operative means of both the $\mathrm{x}$ and y Cartesian coordinates were closer to 0 and the variance of both the $\mathrm{x}$ and $\mathrm{y}$ coordinates were significantly smaller around these means.

\section{Endothelial cell loss}

The pre-operative mean ECD was $1271 \pm 290$ cells $/ \mathrm{mm}^{2}$. At a mean follow-up of 17.2 months, the mean ECD was reduced to $1144 \pm 282$ cells $/ \mathrm{mm}^{2}$, giving a mean reduction of $9.9 \%$. No graft failure was observed in our study throughout the follow-up period.

\section{Discussion}

Prior to the advent of toric IOL, patients with both postPK astigmatism and cataract had to undergo two separate procedures to treat both conditions.
Post-cataract surgery rehabilitation with spectacles or contact lens wear often failed due to anisometropia, high astigmatism, or intolerance to contact lens wear, necessitating a further corneal refractive surgery in these patients. ${ }^{14}$ Six $(66 \%)$ patients in our case series were intolerant to contact lens wear, and one $(11 \%)$ of them found wearing contact lens physically impossible due to weakness in her hands secondary to underlying arthritis.

Corneal astigmatism following PK can be dealt by either incisional corneal techniques, laser refractive surgery, and IOL implantation. ${ }^{14}$ Although incisional techniques like arcuate keratotomy, wedge excision \pm compression sutures serves as a simple and common



Figure 3 Chart of mean Cartesian $\mathrm{x}$ and y coordinates for preoperative corneal astigmatism and post-operative refractive cylindrical error in the corneal plane. Both $\mathrm{x}$ and $\mathrm{y}$ coordinates are closer to 0 with a significant reduction in variance, representing a significant reduction in the post-operative astigmatism.
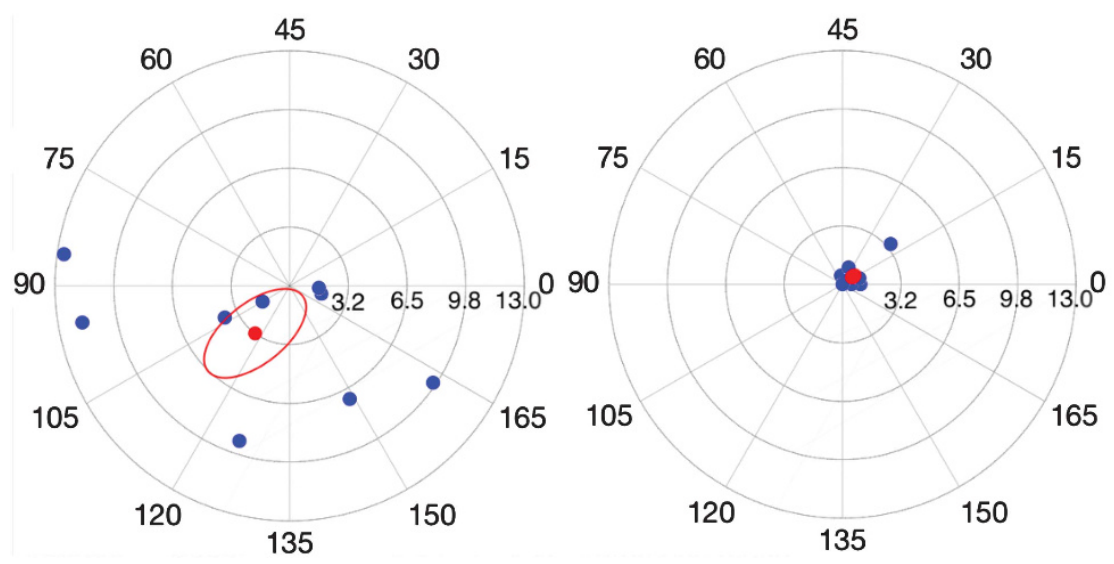

Figure 2 Scatter plot of polar astigmatic vectors for pre-operative corneal astigmatism (a) and post-operative refractive cylindrical error in the corneal plane (b). Note the larger magnitude and distribution of pre-operative astigmatism compared to post-operative result, clustered around 0 . The origin represents an eye that is free of astigmatism. Red point intimates mean value. Scale in D. 
approach to rectify high astigmatism, the post-operative results are subjected to high unpredictability due to variable incision depth and width, and biomechanical response of each individual cornea to the incision. ${ }^{15}$ Three $(33 \%)$ of our patients had previously undergone incisional procedures (including astigmatism keratotomy, wedge resection, and compression sutures), correcting for post-PK astigmatism prior to toric IOL implantation. However, the effect of these procedures in these three patients were suboptimum or regressed over time, resulting in an index of astigmatism of 9.02, 12.63 and $11.67 \mathrm{D}$, respectively, during their presentations for toric IOL implantation. Following toric IOL implantation, astigmatism was significantly improved in these three patients, with a post-operative astigmatism of 3.5, 0.5 and $1 \mathrm{D}$, respectively, suggesting that toric IOL implantation serves as an invaluable therapeutic approach in patients with high post-PK astigmatism who had previously failed to benefit from incisional refractive procedures. Laser refractive procedures such as LASIK and PRK have shown to be effective in correcting post-keratoplasty astigmatism. ${ }^{16,17}$ However, these procedures are associated with inherent problems or complications. For instance, PRK can result in irregularity of the corneal surface and has a high tendency of regression, ${ }^{18}$ whereas LASIK has microkeratome-associated complications. ${ }^{19}$

PE with toric IOL implantation for correcting post-PK astigmatism and cataract was first described in 1999 by Frohn et al. ${ }^{11}$ This was an exciting advancement as this approach allowed correction of both condition with one procedure. Subsequently, good post-operative visual and refractive outcomes had been consistently reported in several case reports. ${ }^{8-10,12}$ Alternatively, toric IOL variants like piggyback and iris-fixated toric IOLs have also been reported to correct post-PK astigmatism in pseudophakic patients. ${ }^{6,20}$

In our series, there were two subsets of patient groups. One group was of phakic patients who underwent PE with toric IOL implantation, and the other was of pseudophakic patients who underwent secondary piggyback toric IOL lens implantation in the ciliary sulcus. However, these two cohort subsets were analyzed as one due to inadequate sample size for subset analysis. Overall, there was a significant improvement in the UDVA following toric IOL implantation. Preoperatively, all eight patients had an UDVA of $\leq 20 / 120$, with seven $(77.7 \%)$ of them having an UDVA of $\leq 6 / 60$. These improved to UDVA of $\geq 6 / 24$ and $\geq 6 / 12$ in eight (88.8\%) and four $(44.4 \%)$ patients, respectively, following the procedure. The fact that only $44.4 \%$ of patients achieved an UDVA of $\geq 6 / 12$ may be attributable to the effects of higher order aberrations induced by the cornea or IOL, irregular astigmatism or by the effects of the curvature of the posterior cornea, none of which were measured in this study. One patient only achieved an UDVA of 6/60. This patient had experienced subincisional iridodialysis at the time of surgery, and as a result had an enlarged pupil aperture postoperatively. We believe that the associated aberrations with an enlarged pupil are the cause for reduced UDVA as the corneal graft, IOLs, and visual axis remain clear, and the patient only had a refractive cylindrical error of 1.00 D. Our visual outcomes are similar to the results reported by Stewart and McAlister, ${ }^{12}$ whom 50\% (four eyes) of their PK patients with astigmatism managed to attain a post-operative UDVA of $\geq 6 / 12$. In terms of correction of cylindrical refractive errors, we observed a mean reduction of $3.05 \pm 3.73 \mathrm{D}$ in our cohort, yielding an average of $78.4 \%$ improvement. This was significantly better that the findings presented by Stewart and McAlister, ${ }^{12}$ who only observed an $\sim 50 \%$ reduction in the cylindrical refractive error. On the other hand, Tahzib et al ${ }^{6}$ reported a mean reduction of cylindrical error of around 95\% in their cohort following Artisan iris-fixated toric IOL lens implantation. The marked differences of outcome-although all were positive-among Stewart and McAlister, ${ }^{12}$ Tahzib et al ${ }^{6}$ and our study may be attributed to the heterogeneity of patient cohort, the difference in the timing of assessing the outcome (eg, UDVA at first month post-operative in Stewart's study, whereas at last follow-up in our study), and the variation in surgical techniques employed by the surgeons. Despite the marked improvement in UDVA and cylindrical error postoperatively, there was lack of significant improvement observed in the BDVA postoperatively in our cohort. This might be due to a good pre-operative BDVA in our cohort, reducing the magnitude of improvement that could be achieved in our patients. Moreover, patients with regular astigmatism are more likely to achieve greater benefit and visual outcomes with a toric IOL when compared to those with irregular astigmatism, which may also be seen following PK.

One of the major concerns of correcting post-PK astigmatism with toric IOL implantation is the rotational stability of the implanted lens. Owing to the poor dilatation of the pupil, we were unable to measure the post-operative rotational stability of the toric IOLs in this cohort. However, as the post-operative UDVA remained stable over a 6-month follow-up period, we assume that the rotational stability of these lenses were good. A common intra-operative difficulty encountered in this study was inadequate pupil dilatation. Achieving good dilatation was found to be even more important when inserting the Torica-s with large Z-haptics IOL into the ciliary sulcus. In anticipation of this problem, a pupilexpanding device (6.25 mm Malyugin Ring) was used at the beginning of such cases.

Endothelial cell loss remains a major concern in toric IOL implantation in patients with previous PK. Tahzib 
et $a{ }^{6},{ }^{6}$ who investigated the outcome of Artisan irisfixated toric IOL implantation, reported a continual endothelial cell loss of $13.8 \pm 18.7 \%, 21.2 \pm 21.8 \%$, and $34.8 \pm 26.3 \%$ at 6 months, 1 year, and 4 years postoperatively, respectively. Acar et $a l^{21}$ reported a mean endothelial cell loss of $20.3 \%$ in patients with previous PK undergoing PE. They found that post-PK patients undergoing extracapsular cataract extraction had a much lower endothelial cell loss $(12.7 \%)$, which is comparable to our cohort. It seems that the endothelial cell loss observed in our cohort is much less compared to PE following PK in these other studies.

We acknowledge that there is a degree of heterogeneity in our cohort of patients with both phakic and pseudophakic patients included in our analysis. Some patients also had previous procedures to correct astigmatism such as wedge excision. However, we believe that we demonstrated and provided enough evidence to show that toric IOL implantation is an option to be considered when managing post-PK astigmatism.

In conclusion, toric IOL implantation with or without simultaneous PE serves as a safe and effective modality in correcting high post-PK astigmatism. However, endothelial cell loss remains a concern with this approach and longerterm outcome will help elucidate this particular issue.

\section{Summary}

What was known before:

- Toric IOL implantation is an effective method to correct high astigmatism following PK.

What this study adds:

- Toric IOL implantation is an effective method to correct high astigmatism following PK with significant improvements in visual acuity and refractive error over a longer time period than previously reported.

\section{Conflict of interest}

The authors declare no conflict of interest.

\section{References}

1 Vail A, Gore SM, Bradley BA, Easty DL, Rogers CA, Armitage WJ. Conclusions of the corneal transplant follow up study. Collaborating surgeons. Br J Ophthalmol 1997; 81: 631-636.

2 Webber SK, Lawless MA, Sutton GL, Rogers CM. LASIK for post penetrating keratoplasty astigmatism and myopia. $\mathrm{Br} \mathrm{J}$ Ophthalmol 1999; 83: 1013-1018.

3 Binder PS. The effect of suture removal on post postkeratoplasty astigmatism. Am J Ophthalmol 1988; 106: 507.

4 Mendicute J, Irigoyen C, Ruiz M, Illarramendi I, Ferrer-Blasco T, Montes-Mico R. Toric intraocular lens versus opposite clear corneal incisions to correct astigmatism in eyes having cataract surgery. J Cataract Refract Surg 2009; 35: 451-458.

5 Raviv T, Epstein RJ. Astigmatism management. Int Ophthalmol Clin 2000; 40: 183-198.

6 Tahzib NG, Cheng YY, Nuijts RM. Three-year follow-up analysis of Artisan toric lens implantation for correction of postkeratoplasty ametropia in phakic and pseudophakic eyes. Ophthalmology 2006; 113(6): 976-984.

7 Tehrani M, Stoffelns B, Dick HB. Implantation of a custom intraocular lens with a 30-diopter torus for the correction of high astigmatism after penetrating keratoplasty. J Cataract Refract Surg 2003; 29(12): 2444-2447.

8 de Sanctis U, Eandi C, Grignolo F. Phacoemulsification and customized toric intraocular lens implantation in eyes with cataract and high astigmatism after penetrating keratoplasty. J Cataract Refract Surg 2011; 37(4): 781-785.

9 Amm M, Halberstadt M. (Implantation of toric intraocular lenses for correction of high post-keratoplasty astigmatism). Ophthalmologe 2002; 99(6): 464-469.

10 Buchwald HJ, Lang GK. Cataract surgery with implantation of toric silicone lenses for severe astigmatism after keratoplasty. Klin Monbl Augenheilkd 2004; 221(6): 489-494.

11 Frohn A, Dick HB, Thiel H-J. Implantation of a toric poly(methyl methacrylate) intraocular lens to correct high astigmatism. J Cataract Refract Surg 1999; 25(12): 1675-1678.

12 Stewart CM, McAlister JC. Comparison of grafted and non-grafted patients with corneal astigmatism undergoing cataract extraction with a toric intraocular lens implant. Clin Experiment Ophthalmol 2010; 38(8): 747-757.

13 Holladay JT, Dudeja DR, Koch DD. Evaluating and reporting astigmatism for individual and aggregate data. J Cataract Refract Surg 1998; 24(1): 57-65.

14 Kuryan J, Channa P. Refractive surgery after corneal transplant. Curr Opin Ophthalmol 2010; 21(4): 259-264.

15 Mendicute J, Irigoyen C, Ruiz M, Illarramendi I, FerrerBlasco T, Montés-Micó R. Toric intraocular lens versus opposite clear corneal incisions to correct astigmatism in eyes having cataract surgery. J Cataract Refract Surg 2009; 35(3): 451-458.

16 Arenas E, Maglione A. Laser in situ keratomileusis for astigmatism and myopia after penetrating keratoplasty. J Refract Surgy 1997; 13: 27-32.

17 Bilgihan K, Ozdek SC, Akata F, Hasanreisoğlu B. Photorefractive keratectomy for post-penetrating keratoplasty myopia and astigmatism. J Cataract Refract Surg 2000; 26(11): 1590-1595.

18 Hersh PS, Brint SF, Maloney RK, Durrie DS, Gordon M, Michelson MA et al. Photorefractive keratectomy versus laser in situ keratomileusis for moderate to high myopia; a randomized prospective study. Ophthalmology 1998; 105(8): $1512-1522$.

19 Webber SK, Lawless MA, Sutton GL, Rogers CM. LASIK for post penetrating keratoplasty astigmatism and myopia. Br J Ophthalmol 1999; 83: 1013-1018.

20 Horn JD. Status of toric intraocular lenses. Curr Opin Ophthalmol 2007; 18: 58-61.

21 Acar BT, Buttanri IB, Sevim MS, Acar S. Corneal endothelial cell loss in post-penetrating keratoplasty patients after cataract surgery: phacoemulsification versus planned extracapsular cataract extraction. J Cataract Refract Surg 2011; 37: 1512-1516. 